\title{
Review Article \\ Prevalence of Multidrug-Resistant Tuberculosis and Associated Factors in Ethiopia: A Systematic Review
}

\author{
Solomon Weldegebreal Asgedom ${ }^{\mathbb{D}},{ }^{1}$ Mebrahtu Teweldemedhin, ${ }^{2}$ and Hailay Gebreyesus ${ }^{3}$ \\ ${ }^{1}$ School of Pharmacy, College of Health Sciences, Mekelle University, Mek'ele, Ethiopia \\ ${ }^{2}$ Unit of Biomedical Science, School of Medicine, College of Health Sciences and Referral Hospital, Aksum University, Aksum, Ethiopia \\ ${ }^{3}$ Unit of Health Education and Promotion, College of Health Sciences and Referral Hospital, Aksum University, Aksum, Ethiopia
}

Correspondence should be addressed to Solomon Weldegebreal Asgedom; solomon.asgedom@mu.edu.et

Received 3 December 2017; Revised 22 February 2018; Accepted 28 February 2018; Published 3 April 2018

Academic Editor: Mario M. D’Elios

Copyright (C) 2018 Solomon Weldegebreal Asgedom et al. This is an open access article distributed under the Creative Commons Attribution License, which permits unrestricted use, distribution, and reproduction in any medium, provided the original work is properly cited.

\begin{abstract}
Background. Multidrug-resistant tuberculosis (MDR-TB) has continued to be a challenge for tuberculosis (TB) control globally. Ethiopia is one of the countries with high MDR-TB burden. Objective. The main purpose of this study was to determine the prevalence of MDR-TB and associated factors in Ethiopia. Methods. A systematic review of the literatures on prevalence of MDR-TB and associated factors was conducted in the country. Results. In our electronic search, 546 citations were depicted. Among the total 546 citations described, a total of 22 articles met eligibility criteria and were included in the review article. According to our review, the prevalence of MDR-TB ranged from 0 to $46.3 \%$. The average mean rate of MDR-TB in Ethiopia was found to be $12.6 \pm 15.9 \%$. The overall prevalence of MDR-TB in all TB cases was estimated to be 1.4\%. From a total of 3849 patients studied, 527 had MDR-TB. Previous exposure to antituberculosis treatment was the most commonly identified risk factor of MDR-TB in Ethiopia. Conclusion. Despite relative decline in incidence of MDR-TB, the distribution and prevalence of MDR-TB continued to be a serious challenge for TB control in Ethiopia. Previous exposure to antituberculosis treatment was also the most common risk factor for MDR-TB. Therefore, strong TB and MDR-TB treatment along with tight introduction of follow-up strategies should be applied for better TB control.
\end{abstract}

\section{Introduction}

Tuberculosis (TB) still continues to be a big public health problem worldwide. It is the second leading cause of death from all infectious diseases globally. Tuberculosis kills an estimate of 1.3 million people every year worldwide [1]. It is also one of the most serious public health challenges in Ethiopia. Ethiopia is ranked second after Nigeria and seventh globally among the 22 countries with high TB burden [2].

The main new barrier that challenges the control of TB is high burden of multidrug-resistant TB (MDR-TB). MDR$\mathrm{TB}$ is a man-made problem due to poor management and quality of antituberculosis drugs. Thus, MDR-TB can be minimized by making tight identification of its predictors [1]. The major contributing factor identified for the spread of MDR-TB is poor infection control [1]. MDR-TB kills an estimate of 110,000 individuals every year and nearly half million new cases of MDR-TB emerge every year. Among the newly emerging MDR-TB cases, only $3 \%$ get serious treatment globally [3].

In 2008, there were 440,000 new MDR-TB cases and 150,000 deaths worldwide [4]. According to the Ethiopian national TB drug resistance surveillance reported, $2.3 \%$ of new TB cases and $17.8 \%$ of previously treated $\mathrm{TB}$ cases were estimated to have MDR-TB [5]. In Africa, there was a report of 69,000 MDR-TB cases [4]. Ethiopia ranked 15th with new cases of MDR-TB each year and is one of the 27 countries with high MDR-TB burden [3]. Even if MDR-TB is highly prevalent in retreated TB cases, the prevalence of MDR-TB in newly diagnosed TB patients has been reported to be $2.8 \%$ $[1,6]$. There are a number of published studies on MDRTB available worldwide. However, accurate data on MDR-TB in Ethiopia is scarce. This review provides an updated and 


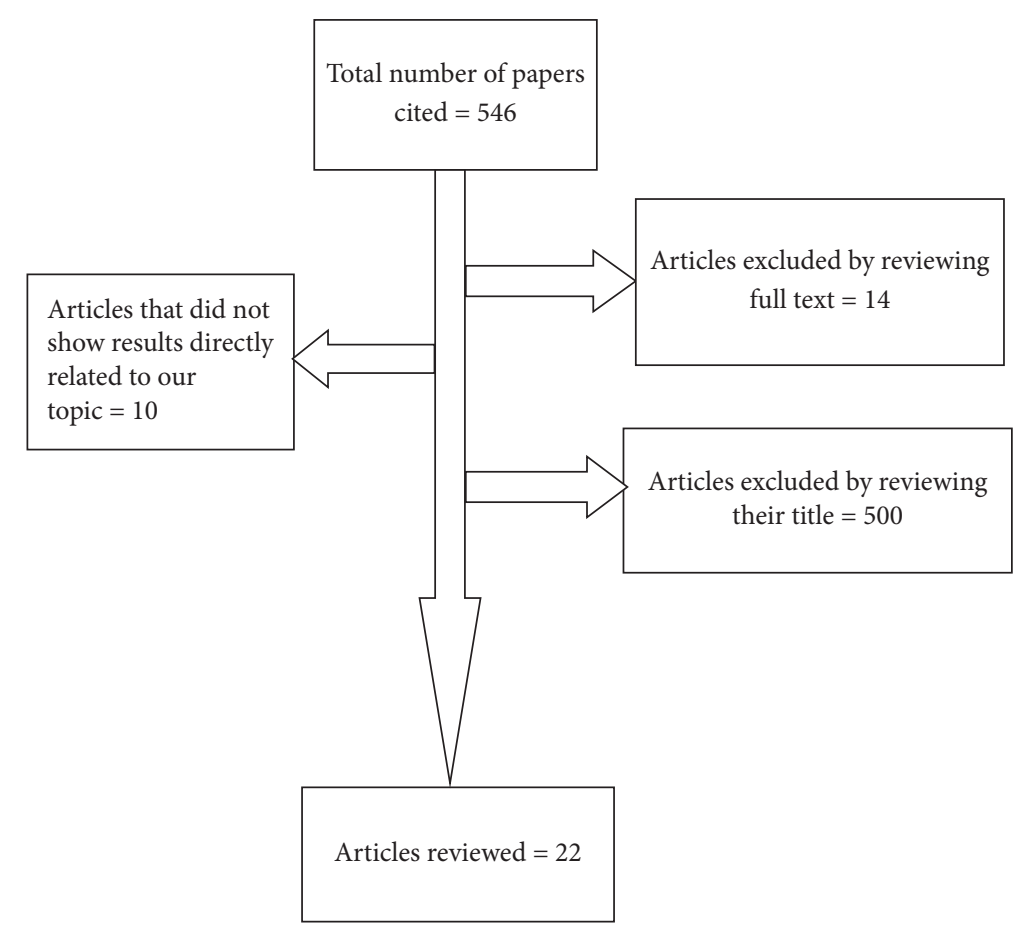

FIGURE 1: Flow diagram of study articles identification.

comprehensive status of the MDR-TB epidemics in Ethiopia. Thus, the main aim of this review was to assess the current prevalence of MDR-TB and factors associated with MDR-TB in Ethiopia.

\section{Methods}

2.1. Search Strategy. Studies that estimated rate of MDRTB and/or identified factors associated with MDR-TB were systematically reviewed. All studies that were published up to 2016 were critically reviewed. We used PubMed search engines and Google Scholar by using medical subject titles MDR-TB, associated factors, and antituberculosis drug resistance. The references of included articles were appropriately scanned to identify additional articles of interest and we used HINARI to access articles without payment.

2.2. Selection of Studies. We used the following criteria to include articles in our study:

(I) Articles with clear objective and methodology

(II) All articles published up to September 2016

(III) Articles that address prevalence of MDR-TB and/or associated factors

(IV) Articles published in English language

(V) Articles with their full texts obtained

2.3. Data Collection Tool and Procedure. Data was collected from the articles through development of data collection checklist. The data collection checklist was pretested in 5 randomly selected articles and it was amended accordingly. The checklist included title, authors' names, year of publication, study time, study design, sample size, rate of MDR-TB, predictors of MDR-TB, and study setting. The prevalence of MDR-TB and/or associated factors reported in all the selected studies was tallied and assessed.

2.4. Operational Definitions. The following definitions related to drug resistance were used [7]:

(i) MDR-TB: TB caused by strains of Mycobacterium tuberculosis which are resistant to at least Isoniazid (INH) and Rifampicin (RMP)

\section{Results}

In our electronic search, 546 citations were depicted. Among the total 546 articles described, 500 were excluded by reviewing their titles, 14 were excluded following full-text review, and 10 were excluded because the title did not show results directly related to our topic. Finally, a total of 22 articles that met eligibility criteria were included in the review article (Figure 1). Among the total 22 articles that met inclusion criteria, 15 studies only reported the prevalence of MDR-TB and they did not asses the factors that were associated with MDR-TB. On the other hand, seven articles reported factors associated with MDR-TB. Among the 7 articles that assessed predictors of MDR-TB, two articles reported findings exclusively focusing on predictors of MDRTB. They did not report prevalence of MDR-TB, because all the patients that were included in the study represented exclusively MDR-TB cases. 


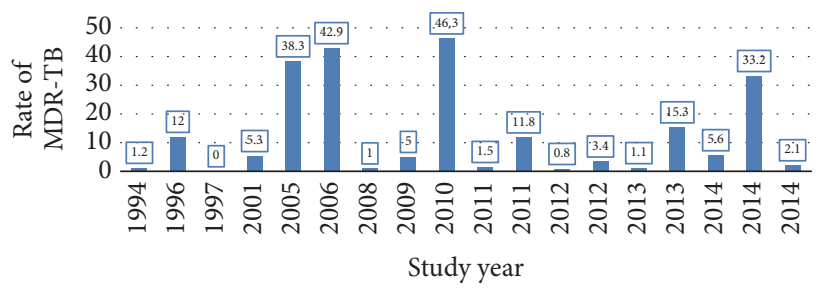

FIgURE 2: Rate of MDR-TB from 1994 to 2014 in Ethiopia.

3.1. Prevalence of $M D R-T B$. In our review, we assessed the overall prevalence of MDR-TB among all TB cases by adding all the number of patients with MDR-TB and dividing it by the total number of studied patients. The total number of patients studied in the review was found to be 3849. Among the total patients studied, 527 had MDR-TB. Thus, the overall prevalence of MDR-TB in this review was found to be $1.4 \%$. The studies were conducted during the period of 1994-2014 from different territories of the country [7-26] (Table 1).

The maximum peak rate of MDR-TB recorded in the country was $46.3 \%$ in 2010 [16] and the minimum rate of MDR-TB was $0 \%$ [7]. The average mean rate of MDR-TB was $12.6 \pm 15.9 \%$, ranging from 0 to $46.3 \%$ [7-26]. In 2006 and 2005, respectively, second (42.9\%) [12] and third (38.3\%) maximum peaks of MDR-TB prevalence were reported [11]. Starting from 2011, a significant decline in rate of MDR-TB was found, despite a 33.2\% record of MDR-TB in 2014 [18$20,22,23,25,26$ ] (Table 1). A zero rate of MDR-TB was recorded in Addis Ababa in 1997 [7]. Generally, there were heterogeneous distribution and prevalence rate of MDRTB report in the country according to the reviewed studies Figure 2.

3.2. Risk Factors Associated with MDR-TB. Our review found that the most commonly reported predictor of MDR-TB was previous exposure to anti-TB treatment $[12,14,15]$. On the contrary, Biadglegne et al. in 2014 showed that there was a negative association between MDR-TB and previous exposure to anti-TB treatment [19]. In the study, newly treated TB cases harbor patients from development of MDR-TB [19]. Another risk factor that was found to be a predictor of MDR-TB was HIV disease [13, 17]. Being male has also been identified to be a predictor of MDR-TB in Ethiopia $[13,16,19]$. The factors that were associated with MDR-TB vary from study time to study time and from study place to study place. The different factors that were associated with MDR-TB are described in Table 2.

\section{Discussion}

This study reviewed the prevalence rate of MDR-TB and the different factors associated with MDR-TB in Ethiopia. In the review, a total of 22 articles that assess prevalence of MDRTB and/or factors associated with MDR-TB were reviewed. The papers were conducted starting from 1994 to 2014. The prevalence rate found as well as the factors associated with MDR-TB was found to be frequently heterogeneous with respect to geographical areas and study periods.
This review study found prevalence of MDR-TB to be $1.4 \%$ among all $\mathrm{TB}$ cases with an average mean rate of $12.6 \pm 15.9 \%$, ranging from 0 to $46.3 \%$ [7-26]. This finding is lower as compared to the $2017 \mathrm{WHO}$ anti-TB drug resistance surveillance data report, which showed that $4.1 \%$ of new and $19 \%$ of previously treated TB cases in the world are estimated to have Rifampicin-resistant or multidrug-resistant tuberculosis (RR-TB/MDR-TB) [29]. This might be due to study design difference, where 2017 MDR-TB WHO report's estimated prevalence was for either Rifampicin resistance or Rifampicin and Isoniazid resistance. However, in our study, resistance to both Rifampicin and Isoniazid was declared as MDR-TB. Moreover, 2017 WHO MDR-TB surveillance report estimated the prevalence of MDR-TB in new TB cases and previously treated cases separately. In our study, we could not estimate prevalence of MDR-TB in new TB cases and retreated TB cases separately due to reported variation of the published papers. Moreover, estimates presented by global control programs are based on samples from government centers comprising potentially susceptible populations or populations where the infection appearance or recurrence is monitored regularly and treated optimally. Therefore, estimates generated from an analysis of these samples may not be a true representation of the TB population in the real world [30, 31]. An Indian systematic review also found MDR-TB prevalence of $23.3 \%$ among all TB cases [32]. This is quite higher when compared to our study. This might be due to variation in patient group studied. The healthcare setup, MDR-TB detection, and the population socioeconomic status variation between the two countries might contribute to the discrepancy.

The lowest record of MDR-TB was in 1997 [7], whereas the highest record of MDR-TB was in 2010 [16]. This highest record of MDR-TB in 2010 as compared to earlier periods might be due to previous antituberculosis exposure of TB cases. Starting from 2010, relatively significant decline in MDR-TB was reported [18-20, 22, 23, 25, 26]. This relative decline in MDR-TB could be due to great emphasis given for quality provision of TB control and diagnostic parameters in the country. The country achieved not only TB control but also MDR-TB treatment of $\geq 75 \%$ in 2015 , making the country one of the three countries with high MDR-TB burden which achieved MDR-TB treatment of $\geq 75 \%$ [33]. This showed that the control of TB and treatment of MDR-TB are escalating from time to time in Ethiopia. Despite improvement in incidence of MDR-TB, this finding showed the spread of MDR-TB and the local control measures for the prevention of MDR-TB are still unsatisfactory. 
TABLE 1: Prevalence of MDR-TB in Ethiopia in the period of 1994-2014.

\begin{tabular}{|c|c|c|c|}
\hline Author & Number of subjects & Study time/period & MDR-TB \\
\hline \multicolumn{4}{|l|}{ Dmissie et al. [7] } \\
\hline New cases & 167 & 1994 & $2(1.2 \%)$ \\
\hline Retreated cases & NS & & NS \\
\hline Total & 167 & & $2(1.2 \%)$ \\
\hline \multicolumn{4}{|c|}{ Ahmed and Hoffner [8] } \\
\hline New cases & NS & 1996 & NS \\
\hline Retreated cases & 107 & & $13(12 \%)$ \\
\hline Total & 107 & & $13(12 \%)$ \\
\hline \multicolumn{4}{|l|}{ Bruchfeld et al. [9] } \\
\hline New cases & 103 & & 0 \\
\hline Retreated cases & 18 & 1997 & 0 \\
\hline Total & 121 & & 0 \\
\hline \multicolumn{4}{|l|}{ Eyob et al. [10] } \\
\hline New cases & 73 & & $2(2.7 \%)$ \\
\hline Retreated cases & 19 & 2001 & $2(10.5 \%)$ \\
\hline Not known & 2 & & 1 \\
\hline Total & 94 & & $5(5.3 \%)$ \\
\hline \multicolumn{4}{|l|}{ Dest et al. [11] } \\
\hline New cases & 73 & & $46(38.3 \%)$ \\
\hline Retreated cases & NS & 2005 & NS \\
\hline Total & 73 & & $46(38.3 \%)$ \\
\hline \multicolumn{4}{|l|}{ Agonafi et al. [12] } \\
\hline New cases & 44 & & $1(2.3 \%)$ \\
\hline Retreated cases & 63 & 2006 & $45(71.4 \%)$ \\
\hline Total & 114 & & $46(42.9 \%)$ \\
\hline \multicolumn{4}{|l|}{ Yimer et al. [13] } \\
\hline New cases & 93 & & $1(1 \%)$ \\
\hline Retreated cases & NS & 2008 & NS \\
\hline Total & 93 & & $1(1 \%)$ \\
\hline \multicolumn{4}{|l|}{ Abebe et al. [14] } \\
\hline New cases & 214 & & $8(4.2 \%)$ \\
\hline Retreated cases & 46 & 2009 & $5(10.9 \%)$ \\
\hline Total & 260 & & $13(5 \%)$ \\
\hline \multicolumn{4}{|l|}{ Abate et al. [15] } \\
\hline New cases & NR & & NR \\
\hline Retreated cases & NR & 2010 & NR \\
\hline Total & 376 & & $174(46.3 \%)$ \\
\hline \multicolumn{4}{|l|}{ Abate et al. [16] } \\
\hline New cases & NR & & NR \\
\hline Retreated cases & NR & 2010-2011 & NR \\
\hline Total & 136 & & $2(1.5 \%)$ \\
\hline \multicolumn{4}{|l|}{ Tessema et al. [17] } \\
\hline New cases & 136 & & $2(1.5 \%)$ \\
\hline Retreated cases & NS & 2011 & NS \\
\hline Total & 136 & & $2(1.5 \%)$ \\
\hline \multicolumn{4}{|l|}{ Hussein et al. [18] } \\
\hline New cases & 93 & & $11(11.7 \%)$ \\
\hline Retreated cases & 9 & 2011 & $1(11.11 \%)$ \\
\hline
\end{tabular}


TABle 1: Continued.

\begin{tabular}{|c|c|c|c|}
\hline Author & Number of subjects & Study time/period & MDR-TB \\
\hline Total & 102 & & $12(11.8 \%)$ \\
\hline \multicolumn{4}{|c|}{ Biadglegne et al. [19] } \\
\hline New cases & 212 & 2012 & $1(0.5 \%)$ \\
\hline Retreated cases & 13 & & 0 \\
\hline Total & 225 & & $2(0.8 \%)$ \\
\hline \multicolumn{4}{|l|}{ Adane et al. [20] } \\
\hline New cases & 77 & & $1(1.29 \%)$ \\
\hline Retreated cases & 12 & 2012 & $2(18.66 \%)$ \\
\hline Total & 89 & & $3(3.37 \%)$ \\
\hline \multicolumn{4}{|l|}{ Nigus et al. [21] } \\
\hline New cases & NR & & NR \\
\hline Retreated cases & NR & $2012-2013$ & NR \\
\hline Total & 606 & & $93(15.3 \%)$ \\
\hline \multicolumn{4}{|l|}{ Shegaw [22] } \\
\hline New cases & NR & & NR \\
\hline Retreated cases & NR & $2012-2014$ & NR \\
\hline Total & 434 & & $9(2.1 \%)$ \\
\hline \multicolumn{4}{|l|}{ Seyoum et al. [23] } \\
\hline New cases & 357 & & $4(1.1)$ \\
\hline Retreated cases & NS & 2013 & NS \\
\hline Total & 357 & & $4(1.1 \%)$ \\
\hline \multicolumn{4}{|l|}{ Mulisa et al. [24] } \\
\hline New cases & NR & & NR \\
\hline Retreated cases & NR & 2013-2014 & NR \\
\hline Total & 265 & & $88(33.2 \%)$ \\
\hline \multicolumn{4}{|l|}{ Hamusse et al. [25] } \\
\hline New cases & 85 & & $2(2.4 \%)$ \\
\hline Retreated cases & 21 & 2013-2014 & $3(14.3 \%)$ \\
\hline Total & 106 & & $5(4.2 \%)$ \\
\hline \multicolumn{4}{|c|}{ Mekonnen et al. [26] } \\
\hline New cases & 88 & & $2(2.3 \%)$ \\
\hline Retreated cases & 36 & 2014 & $5(13.9 \%)$ \\
\hline Total & 124 & & $7(5.6 \%)$ \\
\hline
\end{tabular}

MDR-TB: multidrug-resistant tuberculosis; NR: not reported; NS: not studied.

The commonly identified risk factor of MDR-TB in this review was previous exposure of patients to antituberculosis treatment $[12,14,15,24-27,33]$. Previous antituberculosis treatment exposure is also a common risk factor for MDRTB in many other countries like India, Spain, Iran, Portugal, Europe, and other east African countries [34-41]. The WHO report in 2013 also confirmed that the highest prevalence of MDR-TB among new and previously treated TB cases was $3.6 \%$ and $20.2 \%$, respectively, which is higher in previously treated patients. The high association of previous TB treatment and MDR-TB might be explained due to inappropriate chemotherapy regimens, inadequate or irregular drug supply, unsatisfactory patient or clinician compliance, lack of supervision of treatment, and absence of infection control measures in hospitals [37]. Another factor that was commonly identified as a risk factor was HIV/AIDS [13$15,17,19]$. In addition, alcohol use and treatment failure also were found to be predictors of MDR-TB in Ethiopia [24, 27]. This is in congruence with the finding depicted from Spain [42]. Being male and young age were also other factors that were described as determinant factors of MDR-TB in Ethiopia $[16,19,24]$. However, there were also a number of reports from the country (Ethiopia) which contradict the finding $[12,14,15]$. The discrepancy could be due to difference in study subjects, sample size, and study variables studied.

In this study, there are some limitations. The number of articles that were reviewed was very small due to scarcity of published articles from the country. In the reviewed articles, the study designs used were heterogeneous, which could bias the finding. There was also a discrepancy in reporting of findings. Some studies only studied rate of MDR-TB; other studies studied only factors associated with MDR-TB. In this review study, there was a heterogeneous report of the articles outcome. 


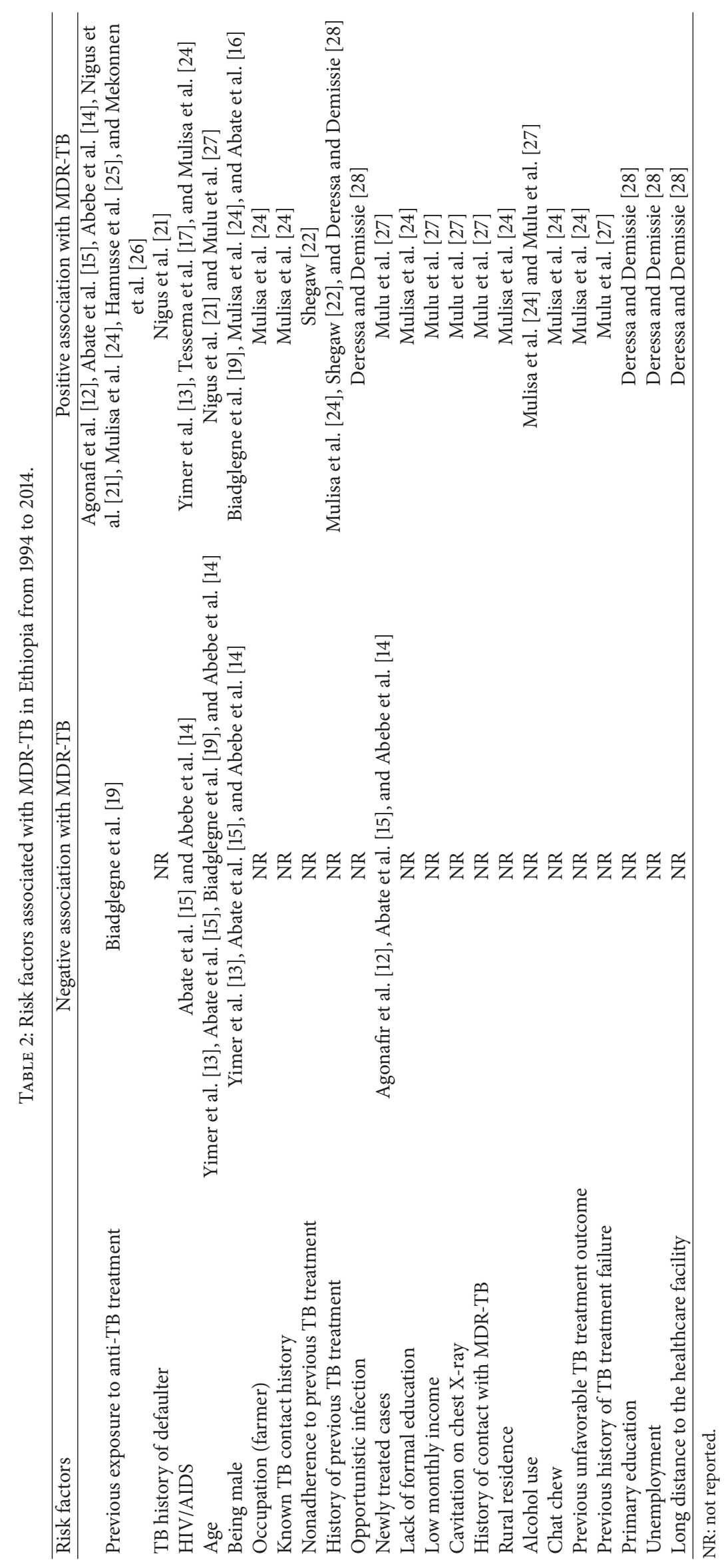




\section{Conclusion}

Even if the incidence of MDR-TB was declined relatively, MDR-TB prevalence and distribution is still a serious public health problem in the country. Prior history of antituberculosis treatment was the most commonly identified risk factor for MDR-TB. Thus, improving TB follow-up strategy in association with provision of strong primary $\mathrm{TB}$ as well as MDR-TB treatment could improve TB control in Ethiopia.

\section{Abbreviations}

HIV: $\quad$ Human immunodeficiency virus

MDR-TB: Multidrug-resistant tuberculosis

TB: Tuberculosis.

\section{Data Availability}

The datasets supporting the conclusions of the study are included in the article. Any additional data will be available on request.

\section{Disclosure}

Solomon Weldegebreal Asgedom is a clinical pharmacist and lecturer at College of Health Sciences, Mekelle University, Ethiopia. Mebrahtu Teweldemedhin is a microbiologist and lecturer at Aksum University, Ethiopia. Hailay Gebreyesus is a lecturer in Aksum University.

\section{Conflicts of Interest}

The authors declare that they have no conflicts of interest.

\section{Authors' Contributions}

Solomon Weldegebreal Asgedom contributed to the conception, review, analysis, and study design and wrote the manuscript. Mebrahtu Teweldemedhin and Hailay Gebreyesus contributed to the study design, supervised the development of the manuscript, and participated in manuscript writing and editing.

\section{Acknowledgments}

The authors acknowledge College of Health Sciences, Mekelle University, for supporting this review.

\section{References}

[1] World Health Organization, "WHO report 2013," Global Tuberculosis control, WHO, Geneva, Switzerland, 2013.

[2] World Health Organization, "WHO Report 2011," Global Tuberculosis Control: Surveillance, planning, Financing WHO/ HTM/TB/2010, WHO, Geneva, Switzerland, 2010.

[3] Federal Ministry of Health of Ethiopia, Guideline for Program And Clinical Management of Drug Resistant Tuberculosis, FMOH, Addis Ababa, Ethiopia, 5th edition, 2009.
[4] World Health Organization, Multidrug and Extensively DrugResistant TB (M/XDR-TB) - 2010 Global Report on Surveillance and Response, World Health Organization, Geneva, Switzerland, 2010.

[5] World Health Organization, "WHO Report 2011," Global Tuberculosis Control: Surveillance, planning, Financing, World Health Organization, Geneva, Switzerland, 2010.

[6] World Health Organization, "WHO report 2011," Global Tuberculosis Control, World Health Organization, Geneva, Switzerland, 2011, (http://www.who.int/tb/data).

[7] M. Dmissie, M. Gebeyehu, and Y. Berhan, "Primary resistance to anti-tuberculosis drugs in Addis Ababa, Ethiopia," International Journal of Tuberculosis and Lung Disease, vol. 1, no. 1, pp. 64-67, 1997.

[8] O. Ahmed and S. E. Hoffner, "Drug resistance in Mycobacterium tuberculosis strains isolated from re-treatment cases of pulmonary tuberculosis in Ethiopia: susceptibility to first-line and alternative drugs," International Journal of Tuberculosis and Lung Disease, vol. 2, no. 7, pp. 580-584, 1998.

[9] J. Bruchfeld, G. Aderaye, I. B. Palme et al., "Molecular epidemiology and drug resistance of Mycobacterium tuberculosis isolates from ethiopian pulmonary tuberculosis patients with and without human immunodeficiency virus infection," Journal of Clinical Microbiology, vol. 40, no. 5, pp. 1636-1643, 2002.

[10] G. Eyob, H. Guebrexabher, E. Lemma et al., "Drug susceptibility of Mycobacterium tuberculosis in HIV-infected and -uninfected Ethiopians and its impact on outcome after 24 months of follow-up," The International Journal of Tuberculosis and Lung Disease, vol. 8, no. 11, pp. 1388-1391, 2008.

[11] K. Dest, D. Asrat, E. Lemma, M. Gebeyehu, and B. Feleke, "Drug susceptibility of mycobacterium tuberculosis isolates from smear negative pulmonary tuberculosis patients, Addis Ababa, Ethiopia," Ethiopian Journal of Health Development, vol. 22, no. 2, pp. 212-215, 2008.

[12] M. Agonafi, E. Lemma, S. Goshu, A. Santhanam, and F. Girmachew, "Phenotypic and genotypic analysis of multidrugresistant tuberculosis in Ethiopia," International Journal of Tuberculosis and Lung Disease, vol. 14, pp. 1259-1265, 2010.

[13] S. A. Yimer, M. Agonafir, Y. Derese, Y. Sani, G. A. Bjune, and C. Holm-Hansen, "Primary drug resistance to anti-tuberculosis drugs in major towns of Amhara region, Ethiopia," APMIS-Acta Pathologica, Microbiologica et Immunologica Scandinavica, vol. 120, no. 6, pp. 503-509, 2012.

[14] G. Abebe, K. Abdissa, A. Abdissa et al., "Relatively low primary drug resistant tuberculosis in southwestern Ethiopia," BMC Research Notes, vol. 5, article no. 225, 2012.

[15] D. Abate, B. Taye, M. Abseno, and S. Biadgilign, "Epidemiology of anti-tuberculosis drug resistance patterns and trends in tuberculosis referral hospital in Addis Ababa, Ethiopia," BMC Research Notes, vol. 5, no. 562, 2012.

[16] D. Abate, B. Taye, M. Abseno, and S. Biadgilign, "Epidemiology of anti-tuberculosis drug resistance patterns and trends in tuberculosis referral hospital in Addis Ababa, Ethiopia," BMC Research Notes, vol. 5, no. 462, 2012.

[17] B. Tessema, J. Beer, F. Emmrich, U. Sack, and A. C. Rodloff, "First- and second-line anti-tuberculosis drug resistance in Northwest Ethiopia," The International Journal of Tuberculosis and Lung Disease, vol. 16, no. 6, pp. 805-811, 2012.

[18] B. Hussein, T. Debebe, A. Wilder-smith, and G. Ameni, "Drug susceptibility test on Mycobacterium tuberculosis isolated from pulmonary tuberculosis patients in three sites of Ethiopia," African Journal of Microbiology Research, vol. 9, pp. 791-796, 7. 
[19] F. Biadglegne, B. Tessema, U. Sack, and A. C. Rodloff, "Drug resistance of Mycobacterium tuberculosis isolates from tuberculosis lymphadenitis patients in Ethiopia," Indian Journal of Medical Research, vol. 140, pp. 116-122, 2014.

[20] K. Adane, G. Ameni, S. Bekele, M. Abebe, and A. Aseffa, "Prevalence and drug resistance profile of Mycobacterium tuberculosis isolated from pulmonary tuberculosis patients attending two public hospitals in East Gojjam zone, northwest Ethiopia," BMC Public Health, vol. 15, p. 572, 2015.

[21] D. M. Nigus, W. M. Lingerew, B. A. Beyene, A. A. Tamiru, M. T. Lemma, and M. Y. Melaku, "Prevalence of Multi Drug Resistant Tuberculosis among Presumptive Multi Drug Resistant Tuberculosis Cases in Amhara National Regional State, Ethiopia," Mycobacterial Diseases, vol. 4, no. 3, 2014.

[22] G. Shegaw, Assessment of multi drug resistant tuberculosis rate and associated factors in public health facilities of Dessie City Administration, North East Amhara, Ethiopia, Addis abeba university, Ethiopia, 2015.

[23] B. Seyoum, M. Demissie, A. Worku, S. Bekele, and A. Aseffa, "Prevalence and drug resistance patterns of mycobacterium tuberculosis among new smear positive pulmonary tuberculosis patients in Eastern Ethiopia," Tuberculosis Research and Treatment, vol. 2014, Article ID 753492, 7 pages, 2014.

[24] G. Mulisa, T. Workneh, N. Hordofa, M. Suaudi, G. Abebe, and G. Jarso, "Multidrug-resistant Mycobacterium tuberculosis and associated risk factors in Oromia Region of Ethiopia," International Journal of Infectious Diseases, vol. 39, pp. 57-61, 2015.

[25] S. D. Hamusse, D. Teshome, M. S. Hussen, M. Demissie, and B. Lindtjørn, "Primary and secondary anti-tuberculosis drug resistance in Hitossa District of Arsi Zone, Oromia Regional State, Central Ethiopia," BMC Public Health, vol. 16, no. 1, article no. 593, 2016.

[26] F. Mekonnen, B. Tessema, F. Moges, A. Gelaw, S. Eshetie, and G. Kumera, "Multidrug resistant tuberculosis: Prevalence and risk factors in districts of metema and west armachiho, Northwest Ethiopia," BMC Infectious Diseases, vol. 15, no. 1, article no. 461, 2015.

[27] W. Mulu, D. Mekonnen, M. Yimer, A. Admassu, and B. Abera, "Risk factors for multidrug resistant tuberculosis patients in amhara national regional state," African Health Sciences, vol. 15, no. 2, pp. 368-377, 2015.

[28] M. A. Deressa and M. Demissie, "Risk Factors of multi-drug resistant tuberculosis in Addis Ababa, Ethiopia: a matched casecontrol study," Open Access Library Journal, vol. 1, pp. 1-8, 2014.

[29] World Health Organization, Global Tuberculosis Report; Multidrug Resistance Tuberculosis (MDR-TB). Update 2017, World Health Organization, 2017.

[30] A. Jain, P. Diwakar, and U. Singh, "Declining trend of resistance to first-line anti-tubercular drugs in clinical isolates of Mycobacterium tuberculosis in a tertiary care north Indian hospital after implementation of revised national Tuberculosis control programme," Indian Journal of Medical Microbiology, vol. 32, no. 4, pp. 430-433, 2014.

[31] M. Hanif, S. Malik, and V. K. Dhingra, "Acquired drug resistance pattern in tuberculosis cases at the state tuberculosis centre," International Journal of Tuberculosis and Lung Disease, vol. 13, no. 1, pp. 74-78, 2009.

[32] V. Goyal, V. Kadam, P. Narang, and V. Singh, "Prevalence of drug-resistant pulmonary tuberculosis in India: Systematic review and meta-analysis," BMC Public Health, vol. 17, no. 1, article no. 817, 2017.
[33] World Health Organization, "WHO report 2015," Global Tuberculosis control, World Health Organization, Geneva, Switzerland, 2015.

[34] A. Faustini, A. J. Hall, and C. A. Perucci, "Risk factors for multidrug resistant tuberculosis in Europe: a systematic review," Thorax, vol. 61, no. 2, pp. 158-163, 2006.

[35] S. K. Sharma and A. Mohan, "Multidrug-Resistant Tuberculosis," Indian Journal of Medical Research, vol. 120, pp. 354-376, 2004.

[36] P. Zhao, X. J. Li, S. F. Zhang, X. S. Wang, and C. Y. Liu, “Social behaviour risk factors for drug resistant tuberculosis in mainland china: A meta-analysis," Journal of International Medical Research, vol. 40, no. 2, pp. 436-445, 2012.

[37] M. L. Antunes, J. Aleixo-Dias, A. F. Antunes, M. F. Pereira, E. Raymundo, and M. F. Rodrigues, "Anti-tuberculosis drug resistance in Portugal," The International Journal of Tuberculosis and Lung Disease, vol. 4, no. 3, pp. 223-231, 2000.

[38] M. Shamaei, M. Marjani, E. Chitsaz et al., "First-line antituberculosis drug resistance patterns and trends at the national TB referral center in Iran-eight years of surveillance," International Journal of Infectious Diseases, vol. 13, no. 5, pp. e236-e240, 2009.

[39] I. Suárez-García, A. Rodríguez-Blanco, J. L. Vidal-Pérez et al., "Risk factors for multidrug-resistant tuberculosis in a tuberculosis unit in Madrid, Spain," European Journal of Clinical Microbiology \& Infectious Diseases, vol. 28, no. 4, pp. 325-330, 2009.

[40] A. Grant, P. Gothard, and G. Thwaites, "Managing drug resistant tuberculosis.”, BMJ (Clinical research ed.), vol. 337, p. all10, 2008.

[41] B. R. Kidenya, L. E. Webster, S. Behan et al., "Epidemiology and genetic diversity of multidrug-resistant tuberculosis in East Africa," Tuberculosis, vol. 94, no. 1, pp. 1-7, 2014.

[42] L. Torres, P. Arazo, J. B. Pérez et al., "Resistance of Mycobacterium tuberculosis in Zaragoza, Spain (1993-1997) and related factors," Medicina Clinica, vol. 115, no. 16, pp. 605-609, 2000. 


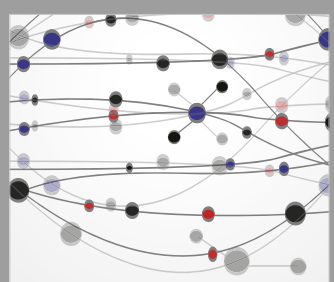

The Scientific World Journal
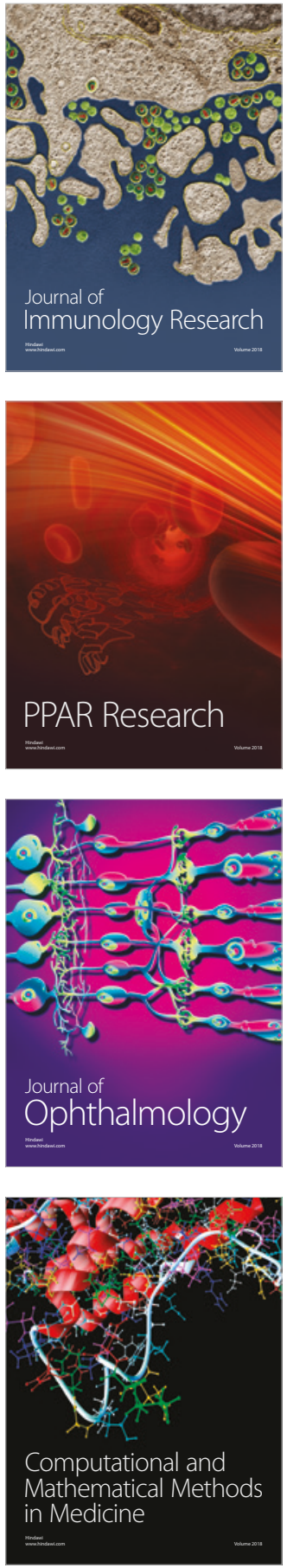

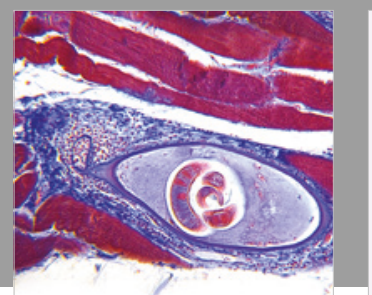

Gastroenterology Research and Practice

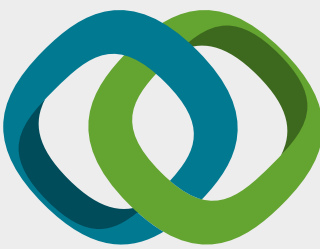

\section{Hindawi}

Submit your manuscripts at

www.hindawi.com
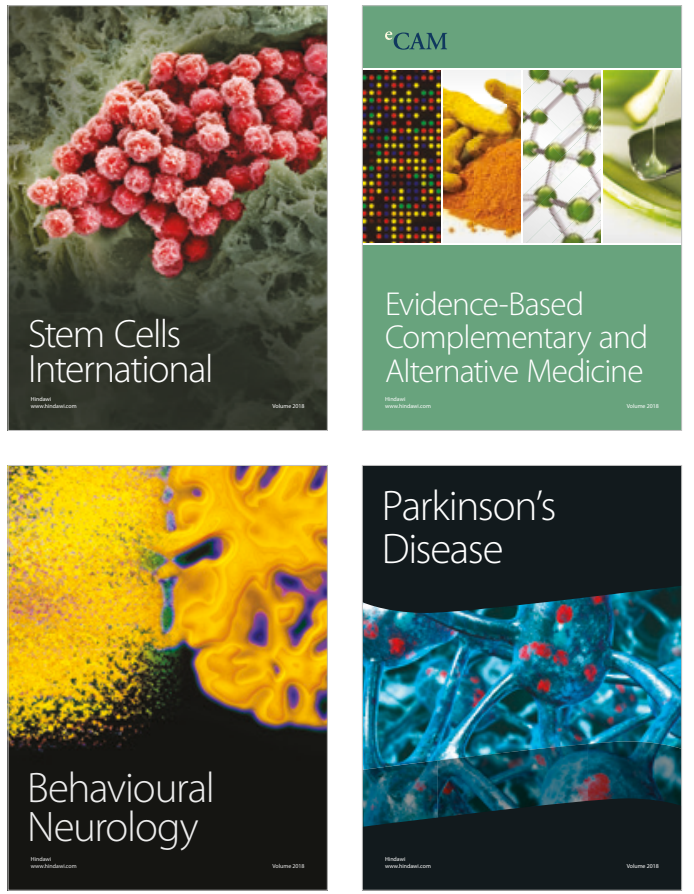

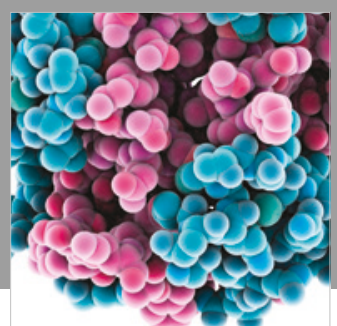

ournal of

Diabetes Research

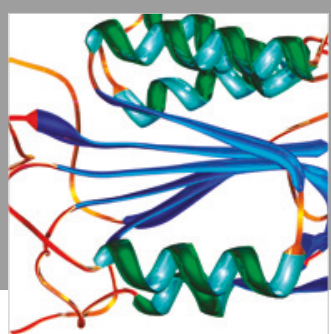

Disease Markers
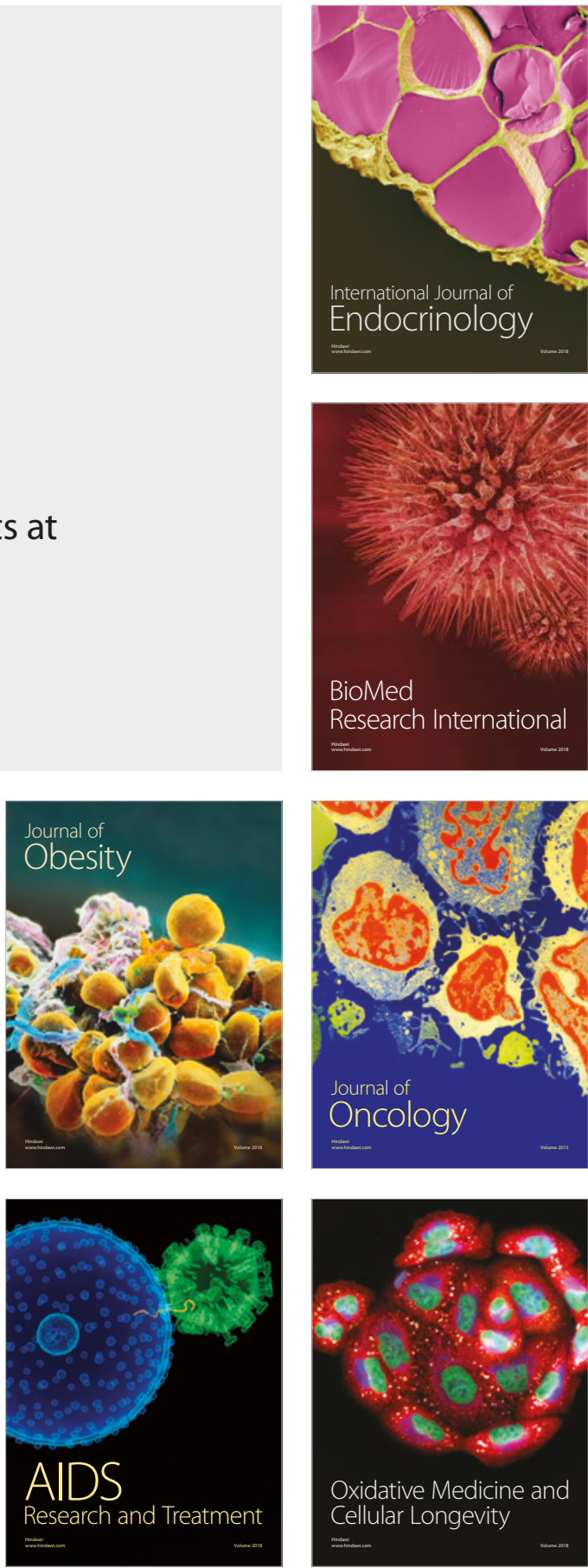